\title{
Pulmonary artery stenosis in hybrid single-ventricle palliation: High incidence of left pulmonary artery intervention
}

\author{
Otto Rahkonen, MD, PhD, ${ }^{a}$ Rajiv R. Chaturvedi, $\mathrm{MD}, \mathrm{PhD},{ }^{\mathrm{a}}$ Lee Benson, $\mathrm{MD},{ }^{\mathrm{a}}$ Osami Honjo, MD, PhD, ${ }^{\mathrm{b}}$ \\ Christopher A. Caldarone, MD, ${ }^{b}$ and Kyong-Jin Lee, $\mathrm{MD}^{\mathrm{a}}$
}

\begin{abstract}
Objective: Pulmonary artery growth is an important determinant of outcome in single-ventricle strategies. Higher rates of pulmonary artery intervention have been reported with hybrid-based palliation when compared with Norwood palliation.
\end{abstract}

\begin{abstract}
Methods: We performed a retrospective review of pulmonary artery growth and clinical outcomes in patients undergoing hybrid-based single-ventricle palliation.

Results: The stage I hybrid procedure was performed in 72 patients between 2004 and 2012, of whom 54 were on a Fontan palliative pathway. Thirty-four infants completed stage II, and 20 infants underwent the Fontan operation. The mean diameters of the right pulmonary artery $(5.6 \pm 1.9 \mathrm{~mm})$ and left pulmonary artery $(5.6 \pm 2.1 \mathrm{~mm})$ were similar before stage II. After stage II, the right and left pulmonary artery diameters were $8.5 \pm 2.1 \mathrm{~mm}$ and $5.8 \pm 1.3 \mathrm{~mm}$, respectively $(P<.001)$, and after the Fontan operation, these were $8.8 \pm 2.0 \mathrm{~mm}$ and $6.4 \pm 1.1 \mathrm{~mm}$, respectively $(P=.002)$. The mean right pulmonary artery $z$ score was normal throughout, but the left pulmonary artery did not maintain a normal size. The cumulative pulmonary artery intervention rate was $50 \%$ at any time after stage II. Fifteen interventions $(88 \%)$ were performed after stage II (35\% during the same hospitalization, $71 \%<60$ days). The most intervened site was the midsection of the left pulmonary artery $(41 \%)$. Initial pulmonary artery intervention was balloon dilation in $59 \%$ of patients and stent implantation in $41 \%$ of patients. Half of patients with initial balloon dilation required reintervention.
\end{abstract}

Conclusions: There is significant risk of left pulmonary artery compromise after the second stage of hybrid palliation associated with a high intervention rate. (J Thorac Cardiovasc Surg 2015;149:1102-10)

See related commentary on page 1111 .

Supplemental material is available online.

The hybrid approach (bilateral pulmonary artery [PA] banding, ductal stenting) for single-ventricle hearts is an alternative to the Norwood procedures (right ventricle [RV]-PA conduit and modified Blalock-Taussig shunt [BTS]) with comparable midterm results. ${ }^{1-6}$ Its theoretic advantage is avoidance of cardiopulmonary bypass surgery, hypothermic circulatory arrest, and the systemic inflammatory reaction during the neonatal period, which

From the Labatt Family Heart Centre, Divisions of Cardiology ${ }^{\mathrm{a}}$ and Cardiovascular Surgery, ${ }^{\mathrm{b}}$ The Hospital for Sick Children, University of Toronto School of Medicine, Toronto, Canada.

Disclosures: Lee Benson reports consulting fees from Medtronic and Siemens. All other authors have nothing to disclose with regard to commercial support.

Received for publication Sept 18, 2014; revisions received Nov 17, 2014; accepted for publication Nov 28, 2014; available ahead of print Jan 13, 2015.

Address for reprints: Kyong-Jin Lee, MD, The Hospital for Sick Children, 555 University Ave, Toronto, Canada M5G 1X8 (E-mail: kyong-jin.lee@sickkids.ca). $0022-5223 / \$ 36.00$

Copyright (C) 2015 by The American Association for Thoracic Surgery

http://dx.doi.org/10.1016/j.jtcvs.2014.11.080 may have long-term implications, particularly for the heart, lungs, and brain.

The complication of PA obstruction has negative clinical implications on the course to and after the Fontan operation. ${ }^{1,5-13}$ Recent studies report smaller PA sizes and a higher incidence of PA intervention in those undergoing the hybrid approach compared with the Norwood procedure after the second operation. ${ }^{5,6,14}$ The PA banding and de-banding process is unique to the hybrid procedure. Excessive banding could impede blood flow and vessel growth. Band migration may compromise lobar branches. During the second stage of hybrid surgery (Damus-Kaye-Stansel anastomosis and bidirectional cavopulmonary connection [BCPC]), the PA band may necessitate more extensive reconstruction of the superior vena cava (SVC) to PA anastomosis and branch PAs. Band-induced alterations in the vessel wall architecture may predispose to obstruction. ${ }^{15,16}$ There may be space constraints for the PA from the newly constructed aorta and adjacent bronchus, potentially further compounded by the rigidity of any ductal stent remnant $^{12,13}$ (Figure 1).

The objective of this study was to perform a detailed review of the PAs of patients who underwent the hybrid procedure for single-ventricle palliation with respect to longitudinal growth, incidence, and timing of PA obstruction, methods of intervention, and impact on clinical outcome. 


\section{Abbreviations and Acronyms \\ $\mathrm{BCPC}=$ bidirectional cavopulmonary connection \\ BTS $=$ Blalock-Taussig shunt \\ HLHS $=$ hypoplastic left heart syndrome \\ LLI = lower lobe index \\ LPA = left pulmonary artery \\ PA = pulmonary artery \\ RPA = right pulmonary artery \\ $\mathrm{RV}=$ right ventricle \\ $\mathrm{SVC}=$ superior vena cava}

\section{MATERIALS AND METHODS Patient Population}

This retrospective study was approved by the hospital research ethics board. Patient selection for the hybrid palliation was decided on a case-by-case basis at our interdisciplinary conference. Between January 2004 and December 2012, a stage I hybrid procedure was performed in 72 patients. No patient underwent a hybrid procedure as a bridge to a Norwood operation. Patients in whom the hybrid stage I procedure was performed as a bridge to transplantation or biventricular repair or as a "salvage" procedure were excluded because serial PA data were not available. A salvage procedure was performed for an infant with prohibitive risks for any type of first-stage single-ventricle palliation. Subanalyses were performed for selected anatomic features, specifically hypoplastic left heart syndrome (HLHS), bilateral SVCs, and right aortic arch.

Our institution has previously described the surgical and interventional techniques used for hybrid single-ventricle palliation. ${ }^{3,13,17}$ Inter-stages I and II are defined as the period between hybrid stages I and II and between stage II and Fontan operations, respectively. Hospital records, echocardiographic and magnetic resonance imaging, cardiac catheterization, and surgical records were reviewed.

\section{Evaluation of Pulmonary Arteries}

Angiography was routinely performed during the stage I hybrid procedure, before stage II and Fontan operations, and after Fontan completion. Starting in September 2008, exit angiography was routinely performed during stage II surgery. These and any additional angiograms were reviewed. The central left pulmonary artery (LPA) and right pulmonary artery (RPA) were measured at 3 points: immediately proximal to the first branch and at the narrowest and largest diameters. The PA diameter reported in the "Results" section refers to the site proximal to the first lobar branch. PA diameters are expressed as $z$ scores. ${ }^{18}$ Range in central PA size was determined by subtracting the smallest from the largest diameter. Nakata index was calculated. ${ }^{19}$ PA stenosis was defined as greater than $50 \%$ narrowing of the blood vessel diameter compared with the adjacent vessel proximally or distally. Diameters of the lower and upper lobe branches were measured. Lower lobe index (LLI) was calculated as the sum of the right and left lower lobe branch cross-sectional areas indexed to body surface area. Symmetry of PAs was evaluated by the ratios of the RPA and LPA diameters and RPA and LPA LLIs. The distance between the PA band and the origin of the first lobar branch was measured at the initial hybrid procedure and the pre-stage II catheterization to determine interval band migration. Migration was defined as being significant if the band caused stenosis or occlusion of a lobar branch. To test our hypothesis of LPA external compression by the reconstructed aorta, aortic measurements were made at the levels of the ascending aorta (neo-aorta), transverse arch (distal to innominate artery), distal arch (at the base of the left common carotid artery), and the diaphragm. A single investigator (OR) obtained all measurements.

\section{Norwood Cases}

During the same period, 88 patients underwent a Norwood stage I procedure (BTS, $\mathrm{n}=77$; Sano shunt, $\mathrm{n}=11$ ). PA intervention rates for these patients are reported.

\section{Statistical Analysis}

Data are presented as mean \pm standard deviation unless otherwise stated. PA intervention and clinical outcome were evaluated with respect to the variables of PA size (absolute and relative), neo-aorta dimensions, PA indices, and LPA/neo-aorta diameter ratio, the narrowest LPA diameter compared with the neo-aorta at all stages. Patients with right aortic arch were excluded from LPA/neo-aorta analysis. Change in PA diameter or "growth" of the branch PAs was analyzed using a paired Student $t$ test. The differential growth of the RPA and LPA after the initial hybrid
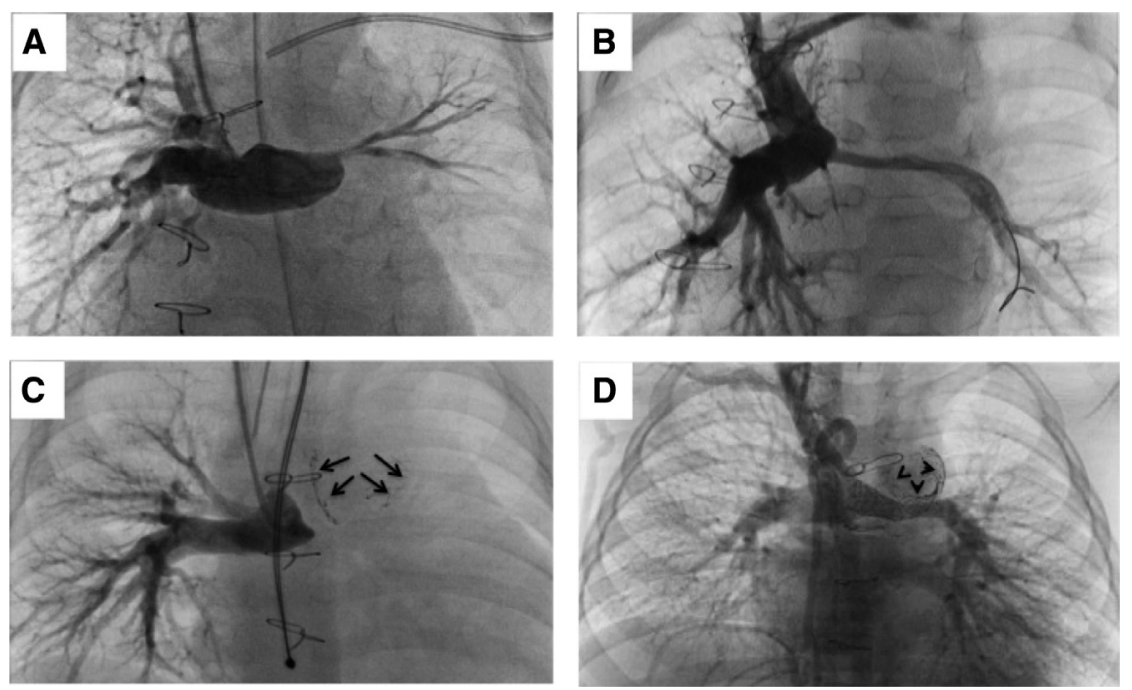

FIGURE 1. Angiograms representative of PA problems after stage II hybrid surgery are shown. A, Severe stenosis distal to LPA patch. B, Asymmetric PA tree. Note the diffusely hypoplastic LPA and well-developed RPA. C, Total occlusion of LPA (arrows; retained ductal stent). D, Proximal and mid-section stenosis of LPA with previously implanted LPA stent. Note the retained ductal stent (arrowheads) at the level of LPA obstruction. 
procedure was compared by a paired $t$ test. Risk for PA intervention was assessed by analysis of variance, and comparative univariate analyses were carried out using the Mann-Whitney $U$ test or Wilcoxon signed-rank test. Freedom from death, transplantation, or reinterventions was estimated using Kaplan-Meier survival analysis. Comparative survival between the HLHS and non-HLHS groups was analyzed using the log-rank test and a stepwise Cox regression analysis.

\section{RESULTS}

Patient characteristics, diagnoses, and clinical course were summarized (Table 1, Figure 2). The 54 patients who underwent hybrid stage I procedure as a singleventricle management strategy of a nonsalvage type were analyzed. No patient was lost to follow-up.

\section{Pulmonary Artery Assessment}

PA and aortic measurements, including Nakata index, LLI, and symmetry data throughout different stages, are shown in Tables E1 and E2.

Before hybrid stage II. At the time of the hybrid stage I procedure, the mean LPA diameter $(3.4 \pm 0.7 \mathrm{~mm})$ was smaller than the RPA $(4.0 \pm 0.6 \mathrm{~mm})(P=.02)$. In the pre-stage II catheterization, the LPA mean diameter of 5.6 $\pm 2.1 \mathrm{~mm}$ was not significantly different from the RPA of $5.6 \pm 1.9 \mathrm{~mm}(P=.76)$.

After stage II. The mean LPA and RPA (stented and nonstented) diameters were $5.8 \pm 1.3 \mathrm{~mm}$ and $8.5 \pm 2.1 \mathrm{~mm}$ $(P<.001)$, respectively, at pre-Fontan catheterization and $6.4 \pm 1.1 \mathrm{~mm}$ and $8.8 \pm 2.0 \mathrm{~mm}(P=.002)$, respectively, at post-Fontan catheterization. Post-Fontan cardiac catheterization $(\mathrm{n}=10,50 \%)$ occurred at a mean age of $3.9 \pm 0.8$ years and $0.7 \pm 0.5$ years after the Fontan. The hilar RPA/LPA ratio was a mean of $1.5 \pm 0.5$ and $1.4 \pm$ $0.4(P=.52)$ at pre- and post-Fontan catheterizations, respectively (Figure $3, A-C$ ). In the subgroup of patients with nonstented vessels, the LPA and RPA mean diameters were $6.2 \pm 1.2 \mathrm{~mm}$ and $8.7 \pm 2.1 \mathrm{~mm}(P=.47)$ at preFontan catheterization and $6.6 \pm 1.2 \mathrm{~mm}$ and $8.5 \pm 2.4$ $\mathrm{mm}(P=.83)$ at post-Fontan catheterization, respectively. Increase in RPA $z$ score occurred from stage I to the postFontan period from $-1.77 \pm 1.03$ to $-0.13 \pm 2.10$ $(P<.05)$, whereas the LPA $z$ score remained small and did not change significantly $(-2.68 \pm 1.62$ at stage $I$ and $-2.16 \pm 1.27$ at post-Fontan catheterization $[P=.36]$ ). At the post-Fontan catheterization, the range in diameter was larger for the LPA, $4.8 \pm 3.8 \mathrm{~mm}$ compared with 1.0 $\pm 1.8 \mathrm{~mm}$ for the RPA $(P<.001)$.

There was no correlation between any of the aortic and LPA diameters at any stage. There were no significant differences in PA size between the HLHS and non-HLHS groups.

Compromise of lobar pulmonary artery branches. The pre-stage II cardiac catheterization demonstrated migration of the PA bands in 9 patients (27\%) with complete loss of a
TABLE 1. Patient characteristics, diagnoses, and clinical course

\begin{tabular}{|c|c|c|}
\hline & $\begin{array}{c}\text { Mean } \pm \text { SD } \\
\text { or n }(\%)\end{array}$ & Range \\
\hline \multicolumn{3}{|l|}{ Demographics } \\
\hline No. of infants & 72 & \\
\hline Male sex & 57 & \\
\hline \multicolumn{3}{|l|}{ Cardiac diagnoses } \\
\hline HLHS & $40(55.5)$ & \\
\hline Borderline LV or Shone complex & $9(12.5)$ & \\
\hline Other diagnosis & $23(32)$ & \\
\hline \multicolumn{3}{|l|}{ Anatomic features } \\
\hline Bilateral SVC & $7(9.7)$ & \\
\hline Right aortic arch & $4(5.6)$ & \\
\hline Bilateral SVC and right aortic arch & $2(2.8)$ & \\
\hline \multicolumn{3}{|l|}{ Clinical outcomes } \\
\hline Bridge to transplantation & $6(8.3)$ & \\
\hline Converted to biventricular repair & $8(11.1)$ & \\
\hline Salvage procedure & $4(5.6)$ & \\
\hline Died & $22(33.3)$ & \\
\hline Stage I & 19 & \\
\hline Stage II & 2 & \\
\hline Fontan & 1 & \\
\hline Transplantation (unintended) & $4(6.1)$ & \\
\hline Stage I & 2 & \\
\hline Stage II & 2 & \\
\hline Fontan & 0 & \\
\hline \multicolumn{3}{|l|}{ Cardiac procedural details } \\
\hline Reverse BTS at stage I & $23(33)$ & \\
\hline DKS anastomosis at stage II & $34(100)$ & \\
\hline \multicolumn{3}{|l|}{ Stage I hybrid* } \\
\hline Age (d) & $13.5 \pm 18.1$ & $1-117$ \\
\hline Weight $(\mathrm{kg})$ & $3.3 \pm 0.5$ & \\
\hline Intensive care unit stay (d) & $7.8 \pm 6.1$ & $2-35$ \\
\hline Hospital stay (d) & $26.0 \pm 12.6$ & $11-64$ \\
\hline Mechanical ventilation (d) & $3.7 \pm 3.1$ & $1-13$ \\
\hline \multicolumn{3}{|l|}{ Stage II } \\
\hline Age (d) & $189.8 \pm 39.2$ & $118-300$ \\
\hline Weight $(\mathrm{kg})$ & $6.5 \pm 1.2$ & \\
\hline Intensive care unit stay (d) & $11.7 \pm 12.8$ & $1-48$ \\
\hline Hospital stay (d) & $21.7 \pm 18.5$ & $6-78$ \\
\hline Mechanical ventilation (d) & $8.0 \pm 12.1$ & $0-45$ \\
\hline \multicolumn{3}{|l|}{ Fontan } \\
\hline Age (y) & $3.1 \pm 0.7$ & $1.9-4.6$ \\
\hline Weight $(\mathrm{kg})$ & $13.9 \pm 1.5$ & \\
\hline Intensive care unit stay (d) & $2.1 \pm 1.1$ & $1-5$ \\
\hline Hospital stay $(\mathrm{d})$ & $24.8 \pm 19.8$ & $7-66$ \\
\hline Mechanical ventilation (d) & $0.7 \pm 1.4$ & $0-5$ \\
\hline \multicolumn{3}{|l|}{ Nonelective percutaneous procedures $\dagger$} \\
\hline After stage II $(\mathrm{n}=34)$ & 48 & \\
\hline PA reinterventions & 32 & \\
\hline SVC interventions & 5 & \\
\hline Other & 19 & \\
\hline
\end{tabular}

$S D$, Standard deviation; $H L H S$, hypoplastic left heart syndrome; $L V$, left ventricle; $S V C$, superior vena cava; $B T S$, Blalock Taussig shunt; DKS, Damus Kaye Stansel; $P A$, pulmonary artery. ${ }^{*}$ Excluding patients bridged to transplantation. $\dagger$ Excluding patients bridged to transplantation, converted to biventricular circulation, or hybrid stage I surgery performed as a salvage procedure. 


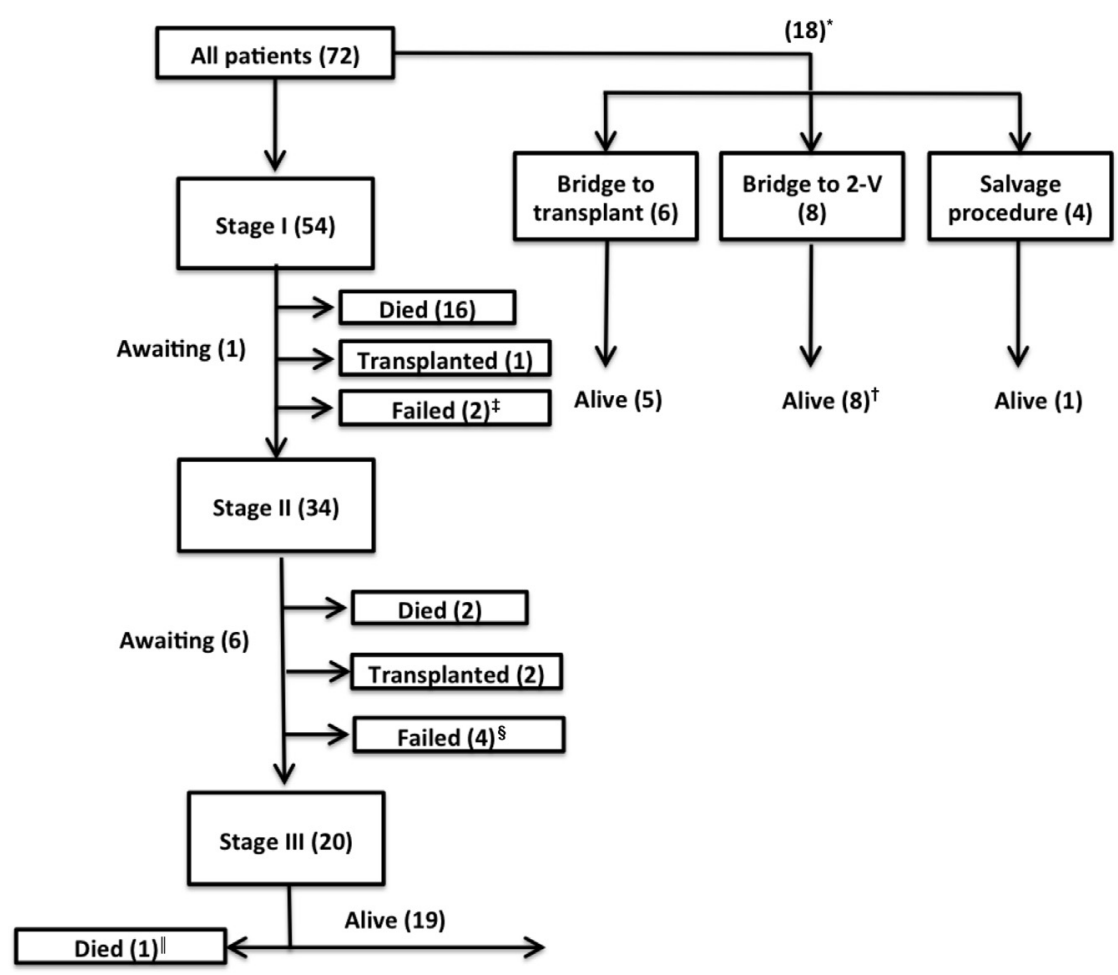

FIGURE 2. Flow chart of outcomes after stage I hybrid procedure. Number of patients is shown in parentheses. *A total of 18 patients were excluded from the study analyses. $\dagger$ One patient underwent transplantation after the biventricular repair. $\ddagger$ Failed, patients were converted to the Norwood ( $\mathrm{n}=3,2$ alive). $\S$ Failed, to proceed to Fontan completion because of unfavorable hemodynamics. ||Patient underwent Fontan takedown.

lobar branch in 4 patients $(11 \%)$. At stage II completion, loss or significant stenosis of branches occurred in 12 patients $(35 \%)$. Subsequent catheterizations demonstrated further complete loss of at least 1 lobar branch in 8 patients. The most common branches involved were left upper lobe $(\mathrm{n}=12)$, right upper lobe $(\mathrm{n}=3)$, and left lower lobe branch $(\mathrm{n}=4)$ (Figure $4, A)$. Left upper lobe compromise occurred in $35 \%$ of patients who had completed stage II.

\section{Pulmonary Artery Interventions}

Inter-stage I. One patient underwent effective balloon angioplasty of the RPA band for severe desaturation. There was minimal flow across the band, and the RPA was diffusely hypoplastic. This patient subsequently underwent a Norwood procedure to promote PA growth without significant improvement.

Stage II post-Fontan. Exit angiography was performed in 14 patients during the second-stage operation. Six patients underwent immediate PA intervention (surgical arterioplasty $[n=3]$, balloon angioplasty $[n=2]$, or both $[n=1]$ ).

A total of 17 patients $(50 \%)$ had significant PA stenosis requiring 32 catheter-based procedures to intervene on 69 sites after the second-stage operation (Figure 4, A). The most common site of obstruction was in the midsection of the LPA ( $41 \%$ of all patients). Significant RPA stenosis occurred in $18 \%$ of patients.
PA interventions consisted of 48 balloon dilations and 21 stent implantations (patients who had initial balloon dilation and then stent implantation during the same procedure were included only in the stent group). Every patient who required PA intervention underwent at least some form of LPA intervention. The central LPA was the most common site of any PA intervention $(64 \%)$ and in particular for stent implantation $(86 \%)$. The other sites of interventions (angioplasty/stent) were the left upper lobe $(13 \% / 0 \%)$, left lower lobe $(23 \% / 5 \%)$, and RPA $(15 \% / 10 \%)$.

Four patients had near or total occlusion of the LPA due to thrombus; 1 patient underwent surgical reopening and LPA patching, and 3 patients underwent successful catheter-based vessel recanalization: stent implantation $(\mathrm{n}=2)$ and thrombectomy using the AngioJet Ultrathrombectomy System (MEDRAD, Inc, Warrendale, Pa) followed by balloon angioplasty $(\mathrm{n}=1)$.

After initial LPA intervention, $47 \%$ of patients required at least 1 additional LPA reintervention and 4 patients required 2 to 3 additional LPA reinterventions (Figure 4, B). A reintervention was performed in $50 \%$ of patients who had balloon dilation as the initial intervention and in $43 \%$ of the patients who initially underwent stent implantation. A third reintervention was indicated only in those patients who initially underwent 

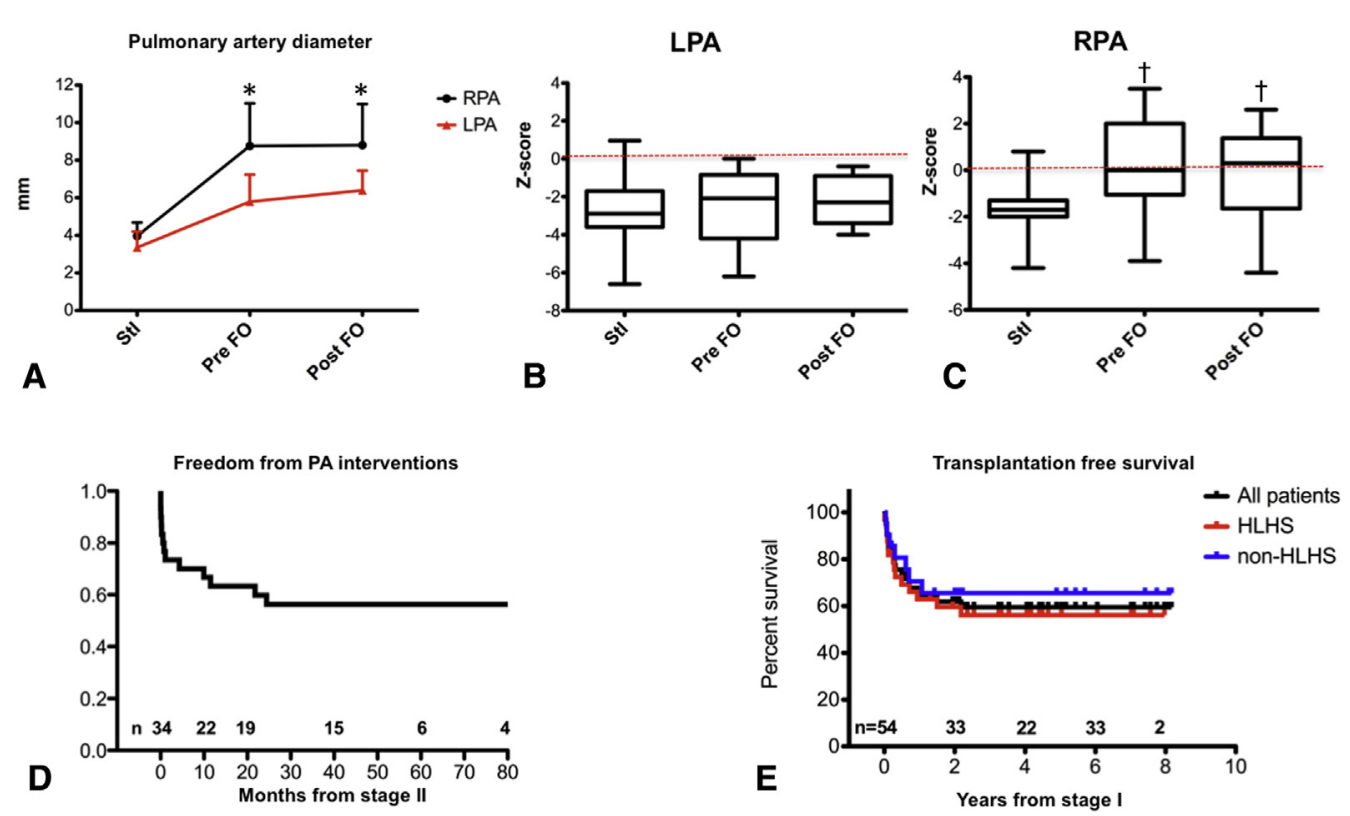

FIGURE 3. A, Diameter of LPA and RPA (millimeters). PA measurements were made immediately proximal to the first lobar branch. Data are shown as mean +1 standard deviation across all patients. $* P<.05$ compared with LPA. B and C, Box plots showing LPA (B) and RPA (C) $z$ scores. Data are expressed as boxplots showing median and interquartile range. Whiskers indicate maximum and minimum values. $\dagger P<.01$ compared with stage I. D, Kaplan-Meier transplantation-free survival curve $(n=54)$, excluding patients bridged to transplantation or biventricular repair, or salvage hybrid procedure. Number of patients is shown above the x-axis. E, Kaplan-Meier curve for PA interventions in patients who underwent hybrid stage II surgery. Starting point is the day of hybrid stage II surgery. Number of patients is shown above the x-axis. Pre FO, Pre Fontan catheterization; Post FO, post Fontan catheterization; $L P A$, left pulmonary artery; StI, Stage I; RPA, right pulmonary artery; PA, pulmonary artery; HLHS, hypoplastic left heart syndrome.

balloon dilation and occurred in $40 \%$ of this patient group. One third of the patients who initially had balloon dilation ultimately underwent stent implantation.

Before PA intervention, the mean PA pressure proximal to the obstruction was $13.8 \pm 4.0 \mathrm{~mm} \mathrm{Hg}$ (range, 10-24 $\mathrm{mm} \mathrm{Hg}$ ). The pressure gradient across the obstruction was $4.4 \pm 4.5 \mathrm{~mm} \mathrm{Hg}$ (range, $0-15 \mathrm{~mm} \mathrm{Hg}$ ) and decreased by $2.6 \pm 4.7 \mathrm{~mm} \mathrm{Hg}$ (range, $0-13 \mathrm{~mm} \mathrm{Hg})(P=.46)$ after intervention.

The majority $(71 \%)$ of the PA interventions occurred during the first 60 days after the stage II procedure (median, 24 days; range, 1-743 days), of which 6 were during the same hospitalization and 2 were in the intensive care unit (Figure 3,D). If additional PA interventions were performed, the median interval between procedures was 72 days (range, $1-650$ days). Five patients $(15 \%)$ required surgical pulmonary arterioplasties at inter-stage II. PA intervention was performed in 2 patients $(10 \%)$ after Fontan completion.

One patient had severe left bronchial compression and LPA stenosis after stage II caused by extrinsic compression by the reconstructed aorta and mediastinal hematoma. The LPA stenosis progressed to complete occlusion and required stenting and then re-stenting for clot formation. LPA stents caused mild worsening of the left bronchus obstruction. The patient was extubated after a prolonged period of mechanical ventilation and remains with residual mild LPA stenosis distal to the stents.

There were no differences in the LPA size or intervention rate between patients who had aortic arch reconstruction incorporating the stented duct $(\mathrm{n}=14)$ and patients with complete stent removal $(\mathrm{n}=20)(P=.21)$. Patients with no PA intervention had a longer duration of PA banding than those who underwent PA intervention (201 \pm 40 days and $167 \pm 33$ days, respectively; $P=.04$ ). SVC obstruction was present in 6 patients after the second-stage operation, with 3 patients undergoing successful stent implantation.

\section{Fontan Candidacy}

After stage II, 6 patients (18\%) were considered too high risk for the Fontan operation. In 5 patients, PA stenosis was a significant negative factor. Two patients underwent transplantation at inter-stage II; 1 had LPA and left pulmonary vein stenoses, and 1 had severe RV dysfunction and cyanosis. Two patients died; 1 had multiple interventions to address LPA and RPA obstructions and subsequently underwent takedown of BCPC and died 37 days later, and 1 had severe proximal stenosis of both branch PAs, severe hypoxia, and sepsis, and died on extracorporeal membrane oxygenation 18 days after the stage II procedure. Two patients had unsuitable hemodynamics to proceed to Fontan completion; 1 had 

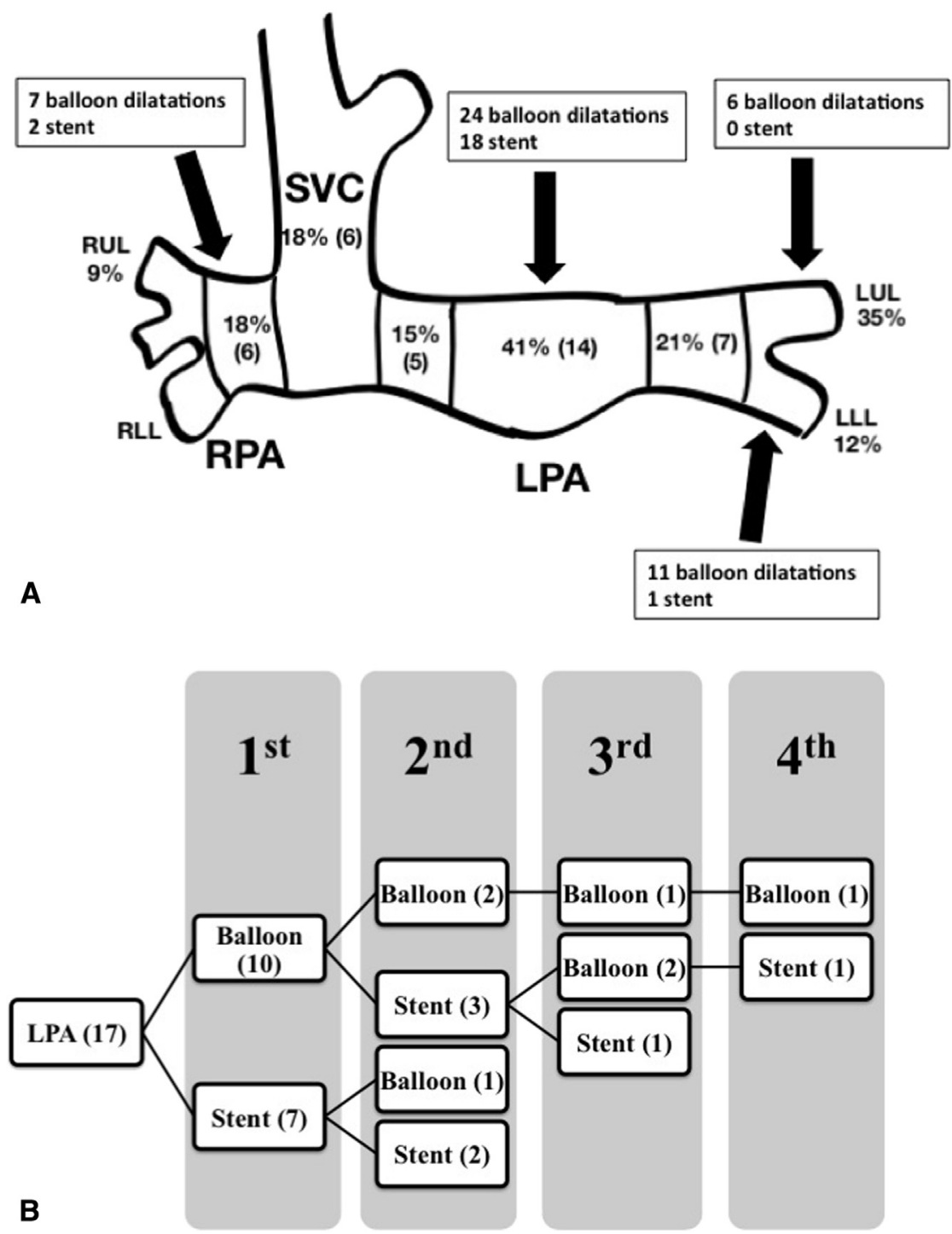

FIGURE 4. A, Site of PA interventions. Percentages demonstrate the site of obstruction in all patients after hybrid stage II surgery ( $\mathrm{n}=34$ ). Percentages below the lobar branches demonstrate the ratio of the patients with stenosed or lost branches. Numbers of interventions at different sites of PAs are shown in boxes (balloon dilatation/stent implantation). Patients who had balloon dilatation and subsequently stent implantation during the same procedure because of the unsuccessful balloon dilatation were included in the stent group only. B, Flow chart of sequential LPA interventions after balloon dilatation (balloon) or stent implantation (stent). Number of patients is shown in parentheses. $L L L$, Left lower lobe; $L P A$, left pulmonary artery; $L U L$, left upper lobe; $R L L$, right lower lobe; $R P A$, right pulmonary artery; $R U L$, right upper lobe; $S V C$, superior vena cava.

BCPC takedown and central shunt creation due to cyanosis and PA stenosis, and 1 had increased pulmonary vascular resistance and persistent LPA obstruction requiring numerous reinterventions. In addition, 2 patients currently at inter-stage II have significant obstruction or hypoplasia of the branch PAs with not yet determined eligibility for Fontan completion. The only significant risk factor in univariate analysis for failure to reach Fontan completion was a smaller LPA size after the hybrid stage II operation (difference between means, $-2.0 \pm 0.8 ; 95 \% \mathrm{CI},-3.6$ to $-0.5 ; P=.013$ ), but this did not remain in multivariate analysis.

\section{Survival and Clinical Outcomes}

The survival and transplantation-free survival were $65 \%$ and $59 \%$, respectively, at a mean follow-up of $3.0 \pm 2.8$ years (Figure 3,E). Nineteen deaths occurred during the follow-up period, of which $16(84 \%)$ occurred at inter-stage I and $2(10 \%)$ occurred at inter-stage II. Four patients underwent successful heart transplantation during inter-stage I $(\mathrm{n}=2)$ and inter-stage II $(\mathrm{n}=2)$. After Fontan completion $(n=20)$, freedom from death or transplantation was $95 \%$ during a mean follow-up of $3.5 \pm 1.5$ years. One patient died after takedown of the Fontan conduit, central shunt insertion for severe desaturation, and chronic chylous 
effusion. No risk factors for survival or transplantation-free survival were identified on multivariate analysis, including HLHS diagnosis, reverse BTS creation, PA size or intervention, bilateral SVC, or right aortic arch.

\section{Norwood Cases: Pulmonary Artery Intervention}

Sixty-three patients have undergone a superior BCPC, and 38 patients have undergone a Fontan operation. After stage I, the shunt or PA intervention rate was $12.5 \%$ : Sano conduit stent \pm RPA stent $(\mathrm{n}=5)$, BTS stent $(\mathrm{n}=2)$, LPA dilation $(\mathrm{n}=2)$, LPA stent $(\mathrm{n}=1)$, and innominate artery stent $(\mathrm{n}=1)$. After the BCPC, the PA intervention rate was $15.9 \%$ (17 procedures in 10 patients). They consisted of 9 patients requiring LPA intervention (stent, $\mathrm{n}=3$ ) and 3 patients requiring RPA intervention (stent, $\mathrm{n}=1$ ). After the Fontan operation, 2 patients underwent PA intervention (5.3\%), both on the LPA (stent $\mathrm{n}=1)$.

\section{DISCUSSION}

Compromise of the pulmonary arterial tree occurring during all stages of single-ventricle palliation is associated with worse outcome. ${ }^{7-11}$ There seems to be a trend toward unilateral PA obstruction dependent on procedure type and the stage of single-ventricle palliation. Ohye and colleagues $^{1}$ report LPA and RPA stenosis of $26 \%$ and $36 \%$, respectively, in the Norwood RV-PA shunt group and $19 \%$ and $27 \%$, respectively, in the MBTS group. ${ }^{1} \mathrm{PA}$ growth is reported to be more symmetric in the RV-PA shunt group compared with the BTS group. ${ }^{1,20,21}$ Smaller LPA diameter has been noted after the second-stage surgery with both the Norwood and hybrid strategies, with recent studies reporting a higher incidence with the hybrid procedure. $^{5,6,8,9,12-14}$ LPA and RPA diameters were similar and within the normal range in the pre-stage II assessment, which was consistent with our previous institutional report of a smaller series. ${ }^{3}$ This report concurs with previous reports that LPA complications begin and persist after the second stage.

The midsection of LPA was particularly prone to obstruction after stage II. Delayed timing of the DamusKaye-Stansel anastomosis and performing the BCPC at the same time may pose technical challenges in LPA reconstruction within a limited space. ${ }^{12}$ The LPA is perfused by passive low-pressure venous flow, and we observed that the long midsection narrowing of the LPA was partly attributable to external compression and twisting of the LPA as its shape conformed to the available space between the pulsatile enlarged neo-aorta and rigid left bronchus. In comparison, only 1 patient $(12.5 \%)$ bridged by hybrid to biventricular repair required PA intervention (RPA) and none of the transplant recipients required PA intervention (data not shown). The sites of RPA and LPA obstruction (ie, at the location of de-banded PAs) suggest that band-induced fibrosis and thinning of the vessel wall may predispose vessels to collapse and obstruction. ${ }^{15,16}$ Davies and colleagues ${ }^{14}$ proposed age more than 90 days at stage II as a risk factor for PA interventions as a consequence of prolonged tissue damage. In our population, age at stage II and longer band duration were not risk factors. ${ }^{16}$

Compromise of lobar PA branches was common in our study (38\%), with half being due to band migration. Davies and colleagues ${ }^{14}$ reported lobar branch loss in $12 \%$ of bilaterally banded PA cases compared with $7.4 \%$ of Norwood cases. The cause of apparent band migration is not known. Hypotheses include a differential growth of the PA on the high-pressure side of the band compared with the low-pressure side or a failure of fixation of the band that has been sutured to the arterial duct.

There is a high incidence of PA-related interventions after the Norwood procedure with PA interventions between $18 \%$ and $33 \%$ after BCPC completion $(15.9 \%$ in our comparative Norwood group). ${ }^{1,6,8,14,20,22}$ In this review, PA reintervention was uncommon after the hybrid stage I but was $50 \%$ after stage II. Dave and colleagues ${ }^{6}$ report a PA intervention rate of $86 \%$ and $31 \%$ in hybrid and Norwood cases, respectively. RPA stenosis occurred most frequently at the RPA-SVC anastomosis. Fortunately, stent implantation was not frequently required because there is risk of "jailing" of the SVC or RPA upper lobe branch. In contrast, our data suggest that in midsection LPA stenosis, primary stent implantation may avoid reintervention. Likewise, others have reported more frequent stenting of the LPA than RPA, ranging from $78 \%$ to $100 \%$ of stents implanted being on the left side. ${ }^{6,14}$ LPA stent implantation may cause tracheobronchial compression. ${ }^{23,24}$ In our review, 1 patient had severe left bronchial compression after stage II. Subclinical compression cannot be excluded in other patients. Airway compression is a limitation for more aggressive stent dilation. A more comprehensive approach to assess for potential airway compromise as a consequence of LPA stent implantation may prevent this complication. More recently, we have checked for potential bronchial compression by bronchoscopy during test LPA balloon dilation.

It is possible that PA stenosis, in particular LPA stenosis, was underdiagnosed. Three-dimensional rotational angiography may be more sensitive than conventional 2-dimensional angiography in the diagnosis, delineation of the mechanism of stenosis, and choice of intervention (surgery vs balloon vs stent), thus decreasing the total number of reinterventions. ${ }^{25}$ For example, PA torsion or external compression would indicate stent implantation over balloon dilation as first-line treatment. In our series, the intervened (balloon or stent) LPA was significantly smaller than the RPA, particularly at the pre-Fontan stage, suggesting the possibility of more aggressive intervention, 
specifically larger stent diameter. Cardiac magnetic resonance imaging may be beneficial in quantifying relative RPA and LPA blood flow in decision-making for all patients with single ventricles. ${ }^{26}$

Similar to the Norwood experience, mortality predominated at inter-stage I in this hybrid population but was not related to PA issues. Survival appears comparable between Norwood and hybrid cases after stages I and II, as well as in preliminary post-Fontan reports., ${ }^{2,3,5,6,14}$ Although there was a high frequency of PA obstruction after stage II hybrid palliation, the majority were amenable to reintervention. $^{2,3,5,6,14}$ Smaller LPA after stage II was a risk factor for decreased Fontan completion on univariate analysis but not on multivariate analysis. Of note, some patients with LPA stenosis were able to complete the Fontan circulation. It is not yet known whether the higher rate of PA intervention with the hybrid procedure will be offset by benefits derived from delay of circulatory arrest or cardiopulmonary bypass. ${ }^{1,22,27,28}$

\section{Study Limitations}

The nonrandomized nature of the enrollment for hybrid versus Norwood palliation is susceptible to selection bias and could affect outcome measures if comparing strategies. Our objective was limited to assessing the PAs in hybrid cases and not intended as a direct comparison with Norwood cases because this has been reported by our and other institutions. ${ }^{5,6,14}$ There may have been a lack of formal uniform parameters for PA reinterventions, but the general approach was to intervene only for very severe obstruction, defined as risk of loss of vessel patency, high cavopulmonary pressures, or lack of clinical progress.

Because of limited follow-up time, the effect of LPA issues on outcome is not comprehensive. For example, 3 patients, currently at inter-stage II, have significant PA issues that may prohibit Fontan completion. Longer-term follow-up studies are needed to show whether PA issues described in our study have a significant effect on patients who undergo the Fontan later in life.

\section{CONCLUSIONS}

Significant PA stenosis requiring intervention is common after the hybrid stage II procedure, particularly in the midsection of the LPA. Stent implantation was more effective than balloon angioplasty. Potential bronchial compression is a consideration during LPA stenting. LPA stenosis may limit Fontan candidacy.

\section{References}

1. Ohye RG, Sleeper LA, Mahony L, Newburger JW, Pearson GD, Lu M, et al. Comparison of shunt types in the Norwood procedure for single-ventricle lesions. N Engl J Med. 2010;362:1980-92.
2. Galantowicz M, Cheatham JP, Phillips A, Cua CL, Hoffman TM, Hill SL, et al. Hybrid approach for hypoplastic left heart syndrome: intermediate results after the learning curve. Ann Thorac Surg. 2008;85:2063-71.

3. Honjo O, Benson LN, Mewhort HE, Predescu D, Holtby H, Van Arsdell GS, et al. Clinical outcomes, program evolution, and pulmonary artery growth in single ventricle palliation using hybrid and Norwood palliative strategies. Ann Thorac Surg. 2009;87:1885-93.

4. Galantowicz M, Cheatham JP. Lessons learned from the development of a new hybrid strategy for the management of hypoplastic left heart syndrome. Pediatr Cardiol. 2005;26:190-9.

5. Baba K, Kotani Y, Chetan D, Chaturvedi RR, Lee KJ, Benson LN, et al. Hybrid versus Norwood strategies for single-ventricle palliation. Circulation. 2012;126: S123-31.

6. Dave H, Rosser B, Knirsch W, Hubler M, Pretre R, Kretschmar O. Hybrid approach for hypoplastic left heart syndrome and its variants: the fate of the pulmonary arteries. Eur J Cardiothorac Surg. 2014;46:14-9.

7. Dasi LP, Krishnankuttyrema R, Kitajima HD, Pekkan K, Sundareswaran KS, Fogel M, et al. Fontan hemodynamics: importance of pulmonary artery diameter. J Thorac Cardiovasc Surg. 2009;137:560-4.

8. Griselli M, McGuirk SP, Ofoe V, Stumper O, Wright JG, de Giovanni JV, et al. Fate of pulmonary arteries following Norwood Procedure. Eur J Cardiothorac Surg. 2006;30:930-5.

9. Knott-Craig CJ, Julsrud PR, Schaff HV, Puga FJ, Danielson GK. Pulmonary artery size and clinical outcome after the modified Fontan operation. Ann Thorac Surg. 1993;55:646-51.

10. Senzaki H, Isoda T, Ishizawa A, Hishi T. Reconsideration of criteria for the Fontan operation - influence of pulmonary artery size on postoperative hemodynamics of the Fontan operation. Circulation. 1994; 89:266-71.

11. Itatani K, Miyaji K, Nakahata Y, Ohara K, Takamoto S, Ishii M. The lower limi of the pulmonary artery index for the extracardiac Fontan circulation. J Thorac Cardiovasc Surg. 2011;142:127-35.

12. Dasi LP, Sundareswaran KS, Sherwin C, de Zelicourt D, Kanter K, Fogel MA, et al. Larger aortic reconstruction corresponds to diminished left pulmonary artery size in patients with single-ventricle physiology. J Thorac Cardiovasc Surg. 2010;139:557-61.

13. Caldarone CA, Honjo O, Benson LN, Van Arsdell GS. Modification of stage II procedure after hybrid palliation (bilateral pulmonary artery banding and ductal stenting) for hypoplastic left-sided heart syndrome: Modified arch reconstruction with retained stented ductus patch. J Thorac Cardiovasc Surg. 2007; $134: 1588-9$.

14. Davies RR, Radtke WA, Klenk D, Pizarro C. Bilateral pulmonary arterial banding results in an increased need for subsequent pulmonary artery interventions. J Thorac Cardiovasc Surg. 2014;147:706-12.

15. Nedorost L, Uemura H, Furck A, Saeed I, Slavik Z, Kobr J, et al. Vascular histopathologic reaction to pulmonary artery banding in an in vivo growing porcine model. Pediatr Cardiol. 2013;34:1652-60.

16. Cordell R, Suh SH. The pulmonary artery lesion after banding: influence of differential materials. Ann Surg. 1974;179:805-11.

17. Caldarone CA, Benson L, Holtby H, Li J, Redington AN, Van Arsdell GS. Initial experience with hybrid palliation for neonates with single-ventricle physiology. Ann Thorac Surg. 2007;84:1294-300.

18. Pettersen MD, Du W, Skeens ME, Humes RA. Regression equations for calculation of z scores of cardiac structures in a large cohort of healthy infants. children, and adolescents: an echocardiographic study. J Am Soc Echocardiogr. 2008;21:922-34.

19. Nakata S, Imai Y, Takanashi Y, Kurosawa H, Tezuka K, Nakazawa M, et al. A new method for the quantitative standardization of cross-sectional areas of the pulmonary arteries in congenital heart diseases with decreased pulmonary blood flow. J Thorac Cardiovasc Surg. 1984;88:610-9.

20. Mery CM, Lapar DJ, Seckeler MD, Chamberlain RS, Gangemi JJ, Kron IL, et al. Pulmonary artery and conduit reintervention rates after Norwood using a right ventricle to pulmonary artery conduit. Ann Thorac Surg. 2011;92: 1483-9.

21. Pruetz JD, Badran S, Dorey F, Starnes VA, Lewis AB. Differential branch pulmonary artery growth after the Norwood procedure with right ventricle-pulmonary artery conduit versus modified Blalock-Taussig shunt in hypoplastic left heart syndrome. J Thorac Cardiovasc Surg. 2009;137: 1342-8.

22. Lai L, Laussen PC, Cua CL, Wessel DL, Costello JM, del Nido PJ, et al Outcomes after bidirectional Glenn operation: Blalock-Taussig shunt 
versus right ventricle-to-pulmonary artery conduit. Ann Thorac Surg. 2007;83: 1768-73.

23. Moszura T, Mazurek-Kula A, Dryzek P, Sysa A. Bronchial compression as adverse effect of left pulmonary artery stenting in a patient with hypoplastic left heart syndrome. Pediatr Cardiol. 2010;31:530-3.

24. Sreeram N, Trieschmann U, Bennink G. Protein losing enteropathy secondary to a pulmonary artery stent. Ann Pediatr Cardiol. 2012;5:51-2.

25. Berman DP, Khan DM, Gutierrez Y, Zahn EM. The use of three-dimensional rotational angiography to assess the pulmonary circulation following cavo-pulmonary connection in patients with single ventricle. Catheter Cardiovasc Interv. 2012;80:922-30.
26. Grosse-Wortmann L, Dragulescu A, Drolet C, Chaturvedi R, Kotani Y, Mertens L, et al. Determinants and clinical significance of flow via the fenestration in the Fontan pathway: a multimodality study. Int J Cardiol. 2013; 168:811-7.

27. Feinstein JA, Benson DW, Dubin AM, Cohen MS, Maxey DM, Mahle WT, et al. Hypoplastic left heart syndrome current considerations and expectations. J Am Coll Cardiol. 2012;59:S1-42.

28. Hsia TY, Cosentino D, Corsini C, Pennati G, Dubini G, Migliavacca F. Use of mathematical modeling to compare and predict hemodynamic effects between hybrid and surgical Norwood palliations for hypoplastic left heart syndrome. Circulation. 2011;124:S204-10.

Readers who found these articles interesting may also like to read the following papers found in recent and future issues of our sister publications, Seminars in Thoracic and Cardiovascular Surgery and Operative Techniques in Thoracic and Cardiovascular Surgery!

Current Readings: Jeffrey Jacobs. Long Term Management of Patients Undergoing Successful Pediatric Cardiac Surgery. Semin Thorac Cardiovasc Surg. Summer 2014;26(2):132-144.

Current Readings: Brian Kogon. Pulmonary Valve Replacement for Pulmonary Valve Insufficiency in Formerly Repaired Tetralogy of Fallot Patients. Semin Thorac Cardiovasc Surg. Expected publication August 2015.

News and Views: Michael Mitchell. Airway Issues in Infants and Other Children with Congenital Heart Disease. Semin Thorac Cardiovasc Surg. Expected publication August 2015.

Original Submission: Meena Nathan. Technical Performance Score as a predictor for post discharge reintervention in valve sparing Tetralogy of Fallot repair. Semin Thorac Cardiovasc Surg. Expected publication April 2015.

Editorial Commentary: Jonathan Chen. Technical performance anxiety: utility of the Technical Performance Scale in predicting later intervention after repair of Tetralogy of Fallot. Semin Thorac Cardiovasc Surg. Expected publication April 2015.

Shi-Joon Yoo. MRI as a decision making tool in congenital heart disease surgery. Oper Tech Thorac Cardiovasc Surg. Summer 2014;19(2):152-163.

Pascal Vouhe. Valve Sparing Konno and HOCM in Children. Oper Tech Thorac Cardiovasc Surg. Summer 2014;19(2):164-178.

Jose Pedro da Silva. Pulmonary root translocation for anatomical repair of congenitally corrected transposition of the Great Arteries. Oper Tech Thorac Cardiovasc Surg. Expected publication February 2015. 
TABLE E1. Pulmonary artery measurements

\begin{tabular}{|c|c|c|c|c|c|}
\hline & Stage I & Pre-stage II & Stage II & Pre-Fontan & Post-Fontan \\
\hline RPA & $4.0 \pm 0.5$ & $5.6 \pm 1.9$ & $6.8 \pm 1.7$ & $8.5 \pm 2.2$ & $8.8 \pm 2.0$ \\
\hline RPA $Z$ score & $-1.77 \pm 1.03$ & $-1.13 \pm 2.03$ & $0.70 \pm 2.07$ & $0.09 \pm 2.07$ & $-0.13 \pm 2.10$ \\
\hline RUL & $2.2 \pm 0.5$ & $3.0 \pm 1.2$ & $2.8 \pm 0.5$ & $3.3 \pm 0.8$ & $4.4 \pm 0.5$ \\
\hline RLL & $3.0 \pm 0.6$ & $5.0 \pm 0.5$ & $4.9 \pm 0.7$ & $6.3 \pm 1.5$ & $7.2 \pm 1.3$ \\
\hline RPA max & $4.0 \pm 0.8$ & $7.3 \pm 2.3$ & $7.6 \pm 1.7$ & $9.8 \pm 2.3$ & $9.2 \pm 1.8$ \\
\hline RPA min & & $5.3 \pm 2.3$ & $5.6 \pm 1.7$ & $7.6 \pm 1.8$ & $8.1 \pm 1.1$ \\
\hline$\triangle \mathrm{RPA}$ & & & $3.4 \pm 2.3$ & $2.1 \pm 2.0$ & $1.0 \pm 1.8$ \\
\hline LPA & $3.4 \pm 0.7$ & $5.6 \pm 2.0$ & $4.8 \pm 1.6$ & $5.8 \pm 1.3$ & $6.4 \pm 1.1$ \\
\hline LPA $Z$ score & $-2.68 \pm 1.62$ & $-1.1 \pm 2.76$ & $-1.78 \pm 2.89$ & $-2.45 \pm 1.95$ & $-2.16 \pm 1.27$ \\
\hline LUL & $2.1 \pm 0.6$ & $2.9 \pm 1.0$ & $2.5 \pm 0.9$ & $2.8 \pm 0.7$ & $3.1 \pm 0.9$ \\
\hline LLL & $2.8 \pm 0.7$ & $4.9 \pm 1.3$ & $4.3 \pm 1.2$ & $5.4 \pm 1.0$ & $5.4 \pm 1.0$ \\
\hline LPA max & $3.4 \pm 0.8$ & $6.7 \pm 2.3$ & $7.7 \pm 1.6$ & $8.3 \pm 2.8$ & $10.8 \pm 4.1$ \\
\hline LPA min & & $5.0 \pm 2.2$ & $3.6 \pm 1.5$ & $5.1 \pm 1.7$ & $6.0 \pm 1.1$ \\
\hline$\Delta \mathrm{LPA}$ & & & $2.9 \pm 2.1$ & $2.7 \pm 2.2$ & $4.8 \pm 3.8$ \\
\hline NeoAo & $12.0 \pm 2.4$ & $16.5 \pm 3.4$ & NA & $21.7 \pm 5.1$ & $23.0 \pm 4.2$ \\
\hline AoArch & $3.9 \pm 1.2$ & $4.9 \pm 1.4$ & NA & $10.6 \pm 3.5$ & $9.3 \pm 1.5$ \\
\hline AortaD & $6.9 \pm 1.0$ & $7.9 \pm 1.4$ & NA & $8.8 \pm 1.0$ & $9.0 \pm 1.0$ \\
\hline
\end{tabular}


TABLE E2. Pulmonary artery measurements classified by need for intervention at stage I, pre-stage II, and pre-Fontan

\begin{tabular}{|c|c|c|c|}
\hline & $\begin{array}{c}\text { Patients } \\
\text { with PA } \\
\text { reintervention } \\
(\mathbf{n}=\mathbf{1 7}) \\
\end{array}$ & $\begin{array}{c}\text { Patients } \\
\text { with no PA } \\
\text { reintervention } \\
(\mathbf{n}=\mathbf{1 7}) \\
\end{array}$ & $P$ value \\
\hline \multicolumn{4}{|l|}{ Stage I } \\
\hline RPA & $4.1 \pm 0.8$ & $3.9 \pm 0.4$ & .56 \\
\hline RPA $Z$ score 1 & $-1.57 \pm 1.10$ & $-1.84 \pm 0.96$ & .46 \\
\hline LPA & $3.5 \pm 0.9$ & $3.4 \pm 0.6$ & .81 \\
\hline LPA $Z$ score & $-2.53 \pm 1.99$ & $-2.80 \pm 1.35$ & .67 \\
\hline MPA & $12.2 \pm 2.0$ & $13.0 \pm 2.7$ & .37 \\
\hline Aorta & $6.8 \pm 1.0$ & $7.5 \pm 0.8$ & .02 \\
\hline Nakata & $114.12 \pm 39.73$ & $103.73 \pm 23.06$ & .39 \\
\hline LLI & $61.52 \pm 28.20$ & $69.08 \pm 13.96$ & .35 \\
\hline LLI ratio & $1.19 \pm 0.33$ & $1.08 \pm 0.23$ & .32 \\
\hline Hilum index ratio & $1.23 \pm 0.33$ & $1.19 \pm 0.25$ & .72 \\
\hline \multicolumn{4}{|l|}{ Pre-stage II } \\
\hline RPA & $5.0 \pm 1.6$ & $5.8 \pm 1.9$ & .27 \\
\hline RPA $Z$ score 1 & $-1.58 \pm 1.92$ & $-0.85 \pm 2.17$ & .34 \\
\hline LPA & $5.8 \pm 2.2$ & $5.2 \pm 1.8$ & .40 \\
\hline LPA $Z$ score & $-0.58 \pm 3.05$ & $-1.37 \pm 2.43$ & .45 \\
\hline Nakata & $176.06 \pm 100.32$ & $166.81 \pm 92.86$ & .80 \\
\hline LLI & $131.47 \pm 57.91$ & $115.60 \pm 48.05$ & .44 \\
\hline LLI ratio & $1.04 \pm 0.51$ & $0.86 \pm 0.59$ & .43 \\
\hline Hilum index ratio & $0.96 \pm 0.38$ & $1.20 \pm 0.43$ & .11 \\
\hline \multicolumn{4}{|l|}{ Pre-Fontan } \\
\hline RPA & $7.9 \pm 2.6$ & $9.0 \pm 2.4$ & .40 \\
\hline RPA $Z$ score & $-1.38 \pm 1.73$ & $0.53 \pm 2.09$ & .12 \\
\hline LPA & $4.9 \pm 1.2$ & $6.3 \pm 1.3$ & .05 \\
\hline LPA $Z$ score & $-3.43 \pm 2.10$ & $-1.81 \pm 1.50$ & .11 \\
\hline Nakata & $170.01 \pm 130.79$ & $189.73 \pm 67.62$ & .68 \\
\hline LLI & $99.04 \pm 31.59$ & $105.94 \pm 26.56$ & .65 \\
\hline LLI ratio & $1.03 \pm 0.25$ & $1.17 \pm 0.36$ & .45 \\
\hline Hilum index ratio & $1.70 \pm 0.76$ & $1.48 \pm 0.51$ & .49 \\
\hline \multicolumn{4}{|l|}{ Post-Fontan* } \\
\hline RPA & $9.33 \pm 1.16$ & $8.57 \pm 2.56$ & .64 \\
\hline RPA $z$ score & $0.70 \pm 1.44$ & $-0.49 \pm 2.32$ & .45 \\
\hline LPA & $6.33 \pm 0.58$ & $6.43 \pm 1.24$ & .90 \\
\hline LPA $z$ score & $-2.00 \pm 1.22$ & $-2.23 \pm 1.38$ & .81 \\
\hline Nakata & $181.42 \pm 60.56$ & $155.22 \pm 58.89$ & .54 \\
\hline LLI & $99.71 \pm 25.26$ & $118.0 \pm 38.39$ & .49 \\
\hline LLI ratio & $0.80 \pm 0.72$ & $1.22 \pm 0.36$ & .26 \\
\hline Hilum index ratio & $1.48 \pm 0.17$ & $1.37 \pm 0.54$ & .76 \\
\hline
\end{tabular}

